\title{
AZT Treatment Induces Molecular and Ultrastructural Oxidative Damage to Muscle Mitochondria \\ Prevention by Antioxidant Vitamins
}

\author{
José García de la Asunción, ${ }^{\star}$ Maria L. del Olmo, ${ }^{*}$ Juan Sastre, ${ }^{\star}$ Arantxa Millán, ${ }^{\star}$ Antonio Pellín, ${ }^{\ddagger}$ Federico V. Pallardó, ${ }^{\star}$ \\ and José Viña* \\ *Departamento de Fisiología and ${ }^{\ddagger}$ Departamento de Patología, Facultad de Medicina, Universidad de Valencia, 46010 Valencia, Spain
}

\begin{abstract}
AIDS patients who receive zidovudine (AZT) frequently suffer from myopathy. This has been attributed to mitochondrial (mt) damage, and specifically to the loss of mtDNA. This study examines whether AZT causes oxidative damage to DNA in patients and to skeletal muscle mitochondria in mice, and whether this damage may be prevented by supranutritional doses of antioxidant vitamins. Asymptomatic HIV-infected patients treated with AZT have a higher urinary excretion $(355 \pm 100 \mathrm{pmol} / \mathrm{kg} / \mathrm{d})$ of 8-oxo-7,8-dihydro-2'-deoxyguanosine (8-oxo-dG) (a marker of oxidative damage to DNA) than untreated controls (asymptomatic HIV-infected patients) $(182 \pm 29 \mathrm{pmol} / \mathrm{kg} / \mathrm{d})$. This was prevented $(110 \pm 79 \mathrm{pmol} / \mathrm{kg} / \mathrm{d})$ by simultaneous oral treatment with AZT plus antioxidant vitamins (C and E). Mice treated with AZT also had a significantly higher urinary excretion of 8-oxo-dG than controls. Skeletal muscle mtDNA of mice treated with AZT had more 8-oxo-dG than controls. $\mathrm{mt}$ lipoperoxidation was also increased and skeletal muscle glutathione was oxidized. These effects may be due to an increased peroxide production by muscle mitochondria of AZT-treated animals. Dietary supplements with vitamins $\mathrm{C}$ and $\mathrm{E}$ at supranutritional doses protect against oxidative damage to skeletal muscle mitochondria caused by AZT. (J. Clin. Invest. 1998. 102:4-9.) Key words: 8-dihydro-2'-deoxyguanosine $\cdot$ AZT $・$ mitochondrial DNA damage $\bullet$ oxidative damage $\bullet$ antioxidant vitamins
\end{abstract}

\section{Introduction}

$3^{\prime}$-azidothymidine, $3^{\prime}$-azido-2', $3^{\prime}$-dideoxythymidine $(\mathrm{AZT})^{1}$ is a potent inhibitor of the replication of HIV and one of the drugs of choice for the treatment of AIDS. The incorporation

Address correspondence to Professor José Viña, Departamento de Fisiología, Facultad de Medicina, Avenida Blasco Ibáñez 17, 46010 Valencia, Spain. Phone: 34-6-38646450; FAX: 34-6-3864642; E-mail: jose.vina@uv.es

Received for publication 5 August 1997 and accepted in revised form 25 March 1998.

1. Abbreviations used in this paper: AST, aspartate aminotransferase; AZT, 3'-azidothymidine, 3'-azido-2',3'-dideoxythymidine; CK, creatine kinase; GSSG, oxidized glutathione; MDA, malondialdehyde; MP, monophosphate; mt, mitochondrial; oxo-8-dG, 8-oxo-7,8-dihydro-2'-deoxyguanosine.

J. Clin. Invest.

(C) The American Society for Clinical Investigation, Inc. 0021-9738/98/07/0004/06 \$2.00

Volume 102, Number 1, July 1998, 4-9

http://www.jci.org of AZT monophosphate (MP) into viral DNA results in premature termination of DNA synthesis (1). The major limitation in the use of AZT is the occurrence of severe side effects (2). AIDS patients who receive long-term therapy with AZT frequently suffer from toxic mitochondrial (mt) myopathy. Typical features of this myopathy are ragged red fibers and paracrystalline inclusions in mitochondria (3). This has been attributed to damage to mitochondria and to mtDNA depletion (4). mtDNA depletion in muscle is probably due to the AZT-induced inhibition of DNA polymerase gamma, which is responsible for the replication of mtDNA (4). Moreover, decreased mtDNA and $\mathrm{mt}$ polypeptide synthesis were found in vitro (5). A single study in 1991 proposed that AZT causes oxidation of deoxyguanosine to yield 8-oxo-7,8-dihydro-2'-deoxyguanosine (8-oxo-dG) in DNA from the mitochondria of experimental animals (6). The role of mtDNA in cell physiology and medicine has been emphasized previously (7). Manifestations of $\mathrm{mt}$ diseases are thought to be due, at least in part, to increased free-radical formation $(7,8)$. We recently observed that there is a correlation between glutathione oxidation and mtDNA damage and that age-associated mtDNA damage can be prevented by administration of antioxidant vitamins (9). The aim of this work was to test whether AZT causes oxidative damage to mitochondria and whether this can be prevented by administration of supranutritional doses of antioxidant vitamins.

We have found that AZT causes an increase in the urinary excretion of 8-oxo-dG in humans and mice, and that it also causes an oxidation of mtDNA, mt glutathione, and lipids (measured as malondialdehyde [MDA]). This oxidative damage may be due to an increased peroxide production by muscle mitochondria from AZT-treated animals. Antioxidants revert this oxidative damage and also the ultrastructural changes in mitochondria caused by AZT.

\section{Methods}

Chemicals. RNAase (E.C.3.1.27.5) from bovine pancreas was purchased from Boehringer-Mannheim (Mannheim, Germany). Water and methanol (HPLC grade) were from Merck (Darmstadt, Germany). Nuclease P1 (E.C.3.1.30.1) was from P. Citricum. Alkaline phosphatase type III-L (C.E.3.1.3.1) was isolated from Escherichia coli. Glutathione-S-transferase (E.C.2.5.1.18) was isolated from equine liver. GSH, oxidized glutathione (GSSG), 8-oxo-dG, AZT, (3'-azido-3'-deoxythymidine) $N$-ethylmalemide (NEM), bathophenanthroline disulfonic acid (BPDS), Mops, BSA, and all other reagents were purchased from Sigma Chemical Co. (St. Louis, MO).

Patients. We analyzed urine from $2330 \pm 3$-yr-old male adults weighing $70 \pm 7 \mathrm{~kg}$. Urine samples were collected from each individual $24 \mathrm{~h}$ void and stored at $-30^{\circ} \mathrm{C}$ until analysis. Four groups were studied: $(A)$ healthy controls, $(B)$ HIV-positive patients (who had not received AZT) with $570 \pm 261 \mathrm{CD}_{4}+/ \mu \mathrm{l}$, (C) HIV-positive patients treated with AZT (Retrovir ${ }^{\circledR}, 250 \mathrm{mg} / 12 \mathrm{~h}$ ) over 12-24 mo with $382 \pm 141 \mathrm{CD}_{4}+/ \mu \mathrm{l}$, and $(D)$ the same HIV-positive patients who were 
included in group $C$ (treated with AZT), but treated simultaneously with AZT and antioxidants; vitamin $\mathrm{C}$ (ascorbic acid, $1 \mathrm{~g} / \mathrm{d}$ ) and vitamin $\mathrm{E}$ ( $\alpha$-tocopherol, $0.6 \mathrm{~g} / \mathrm{d}$ ), given orally for $1 \mathrm{mo}$. The procedures were carried out in accordance with the Helsinki Declaration of 1975 as revised in 1983. Each patient gave written, informed consent for the administration of antioxidant vitamins. This study was approved by the Research Committee of the Facultad de Medicina de Valencia.

Animals. Male OF1 mice (IFFA-Credo, Barcelona, Spain) were maintained on a $12 \mathrm{~h} / 12 \mathrm{~h}$ light/dark cycle at $22^{\circ} \mathrm{C}$. Mice were fed a standard laboratory diet from Letica (Barcelona, Spain), containing $590 \mathrm{~g}$ of carbohydrates, $30 \mathrm{~g}$ of lipids, and $160 \mathrm{~g}$ of protein per kilogram of diet, and tap water ad libitum. Animals treated with antioxidant vitamins were fed on the same diet but supplemented with vitamin C (ascorbic acid, $10 \mathrm{~g} / \mathrm{kg}$ diet) and vitamin E ( $\alpha$-DL-tocopherol, $0.6 \mathrm{~g} / \mathrm{kg}$ diet) for $65 \mathrm{~d}$ before killing; this resulted in a daily intake of $1.25 \mathrm{~g} / \mathrm{kg}$ body wt/d (vitamin C) and $75 \mathrm{mg} / \mathrm{kg}$ body wt/d (vitamin E). Treatment with vitamins was started 1 mo before the treatment with AZT. We pretreated the animals for 1 mo with vitamins $\mathrm{C}$ and $\mathrm{E}$ because previous work has shown that a minimum treatment period of 2-4 wk is required to obtain maximum, stable plasma and tissue levels of these vitamins $(10,11)$. Animals were divided into three groups: $(A)$ controls, $(B)$ mice treated with AZT, and $(C)$ mice treated with AZT and dietary antioxidants. AZT was administered in drinking water $(10 \mathrm{mg} / \mathrm{kg}$ body wt/d) for $35 \mathrm{~d}$. When animals received an antioxidant-supplemented diet their food intake and body weights were similar to those of the controls (results not shown). 5-mo-old mice were anesthetized with sodium pentobarbital $(60 \mathrm{mg} / \mathrm{kg}$ body wt, intraperitoneally) and killed by decapitation between 9:00 and 11:00 a.m. to minimize circadian variations of the parameters studied.

Isolation of mitochondria. Isolation of mitochondria was performed using differential centrifugation as described by Rickwood et al. (12).

Isolation and preparation of $m t D N A$ samples for HPLC. Extraction of mtDNA was accomplished according to the method described by LaTorre et al. (13) adapted to skeletal muscle (9). The purity of mtDNA was determined spectrophotometrically by measuring the absorbance ratio at $260 / 280 \mathrm{~nm}$. The value found was $1.7-1.8$, in agreement with previous studies (14). The presence of mtDNA was confirmed by a restriction mapping as well as a PCR analysis using oligonucleotides specific for the mtDNA sequence (15). The amount of nuclear DNA contamination in our mtDNA preparations was $<5 \%$, as determined by gel electrophoresis followed by densitometry. The amount of DNA hydrolyzed for injection onto the HPLC with electrochemical detection was $10-40 \mu \mathrm{g}$ as determined by ultraviolet analysis (absorbance at $260 \mathrm{~nm}$ ). This was in the range suitable for analysis of 8-oxo-dG in mtDNA samples (16).

Analysis of urinary 8-oxo-dG. Purification and detection of 8-oxo-dG was performed according to the method of Shigenaga et al. (17) with slight modifications (18).

Measurement of 8-oxo- $d G$. This metabolite was measured as described by Shigenaga et al. (19) based on reverse-phase HPLC combined with electrochemical detection. Electrochemical detection of
8-oxo-dG was performed using an ESA Coulochem dual coulometric detector (model 5200; ESA, Bedford, MA) equipped with a 5011 analytical cell.

Assays. Standard enzymatic methods were used to measure levels of creatine kinase (CK), aspartate aminotransferase (AST), and lactate dehydrogenase (LDH) in mouse serum (20).

Measurement of glutathione. GSH was measured spectrophotometrically using glutathione- $S$-transferase (21). GSSG was assayed by an HPLC method with detection at $365 \mathrm{~nm}$, which we recently developed to measure GSSG in the presence of a large excess of GSH $(22,23)$.

Measurement of MDA. MDA content was determined in skeletal muscle mitochondria using an HPLC method described by Wong et al. (24) that determines MDA formed from lipoperoxides. mt lipoperoxides are hydrolyzed by boiling in diluted phosphoric acid. MDA reacts with thiobarbituric acid to form an adduct, which is detected by HPLC. The calibration curve was assayed using tetramethoxypropane, which undergoes hydrolysis to liberate stoichiometric amounts of MDA (25).

Measurement of peroxide production by mitochondria. After isolation, skeletal muscle mitochondria were suspended in ice-cold respiratory buffer (with $0.3 \mathrm{M}$ sucrose, $1 \mathrm{mM}$ EGTA, $5 \mathrm{mM}$ Mops, $0.1 \%$ BSA, and $5 \mathrm{mM} \mathrm{KH} \mathrm{PO}_{4}$ adjusted to $\mathrm{pH} 7.4$ with $\mathrm{KOH}$ ) and were used to measure the production of peroxides with an Epics Elite II flow cytometer (Coulter Electronics, Hialeah, FL). Dihydrorhodamine 123 was used as fluorochrome on incubation at $37^{\circ} \mathrm{C}$ for $30 \mathrm{~min}$ and was excited with an argon laser tuned at $488 \mathrm{~nm}$. Colorless dihydrorhodamine 123 is oxidized outside mitochondria by $\mathrm{H}_{2} \mathrm{O}_{2}$-dependent reactions to the fluorescent product rhodamine 123, which stains mitochondria $(26,27)$. Rhodamine 123 is a cationic fluorescent lipophilic dye with a delocalized positive charge. It is readily taken up by active mitochondria without inducing cytotoxic effects. The $\mathrm{mt}$ membrane potential is the driving force for rhodamine 123 uptake by mitochondria (26). This reduced rhodamine has been used to monitor reactive oxygen intermediates in different cellular and subcellular models $(27,28)$.

The gate was set on logarithm of forward and side scatter to always include mitochondria with the same morphological properties. Thus, changes in fluorescence were independent of the particle size.

Electron microscopy of mouse muscle samples. Skeletal muscle samples (gastrocnemius) were obtained for electron microscopy. Samples were fixed in $0.1 \mathrm{mM}$ phosphate buffer $(\mathrm{pH} 7.2)$ containing $2.5 \%$ glutaraldehyde for $2 \mathrm{~h}$, and then postfixed in $0.1 \mathrm{mM}$ phosphate buffer ( $\mathrm{pH} 7.2$ ) containing $2 \%$ osmium tetroxide for a further $2 \mathrm{~h}$. After embedding the sample blocks in Epon, ultrathin sections were cut with the ultramicrotome Ultratome III (Ultratome, Uppsala, Sweden) and then contrasted with uranyl acetate and lead citrate for transmission electron microscopy. Electron microphotographs were taken with an electron microscope (JEOL, Tokyo, Japan) JEM 11 B.

Statistics. Results are expressed as the mean \pm SD. Statistical analyses were performed by the least significant difference test, which consists of two steps. First an ANOVA was performed. The null hy-
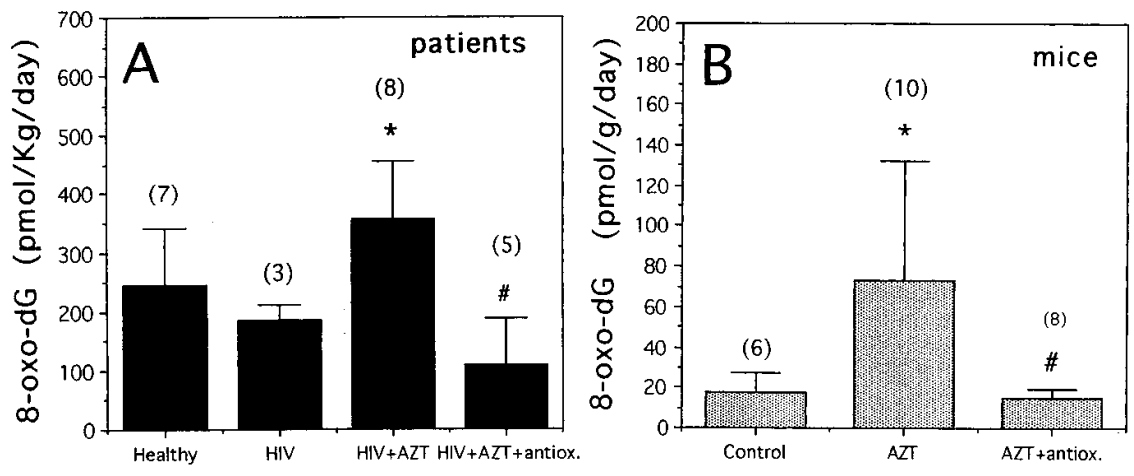

Figure 1. Levels of 8-oxo-dG in urine from HIV-seropositive patients $(A)$ and from mice $(B)$ treated with AZT and antioxidant vitamins (C and E). Statistical significance is expressed as follows: $* P<0.05$ versus the HIV group (untreated patients, $A$ ) or versus the control group $(B) ;{ }^{\#} P<0.05$ versus the HIV + AZT group $(A)$ or versus the AZT-treated group $(B)$. 


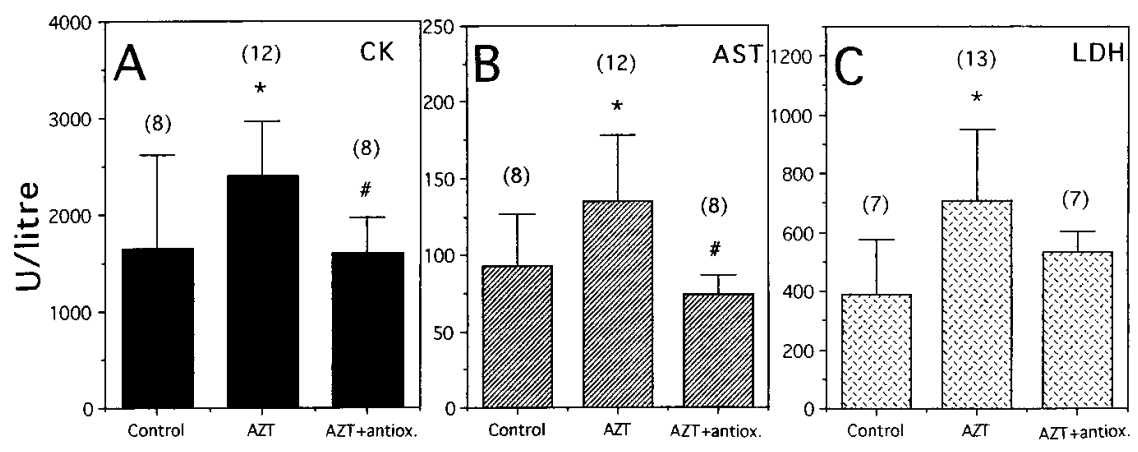

Figure 2. Serum activities of enzymes that are markers of muscle damage in AZT-treated mice. Protection by vitamins $\mathrm{C}$ and E. $(A) \mathrm{CK}$; (B) AST; and $(C)$ LDH. Statistical significance is expressed as follows: $* P<0.05$ versus the control group; ${ }^{\#} P<0.05$ versus the AZTtreated group. pothesis was accepted for all numbers of those set in which $\mathrm{F}$ was nonsignificant at the level of $P \leq 0.05$. Then the sets of data in which F was significant were examined by the two-tailed $t$ test using $P \leq$ 0.05 as the critical limit.

\section{Results}

DNA damage caused by AZT in humans: urinary excretion of 8-oxo-dG in HIV-infected patients treated with AZT. Urinary excretion of 8-oxo-dG is an indicator of oxidative damage to DNA $(17,19)$. Fig. $1 A$ shows that asymptomatic HIV patients who receive AZT ( $250 \mathrm{mg} / 12 \mathrm{~h}$ ) have a marked increase of 8 -oxo-dG in urine $(355 \pm 100 \mathrm{pmol} / \mathrm{kg} / \mathrm{d}, n=8)$ when compared with healthy controls $(243 \pm 99 \mathrm{pmol} / \mathrm{kg} / \mathrm{d}, n=7, P<$ $0.05)$. This can be prevented by oral administration of supranutritional doses of antioxidants, which decreases the urinary excretion of 8-oxo-dG to $110 \pm 79 \mathrm{pmol} / \mathrm{kg} / \mathrm{d}(n=5), P<0.05$ (Fig. $1 A$ ). However, asymptomatic HIV-positive patients who had not received AZT showed 8-oxo-dG values $(183 \pm 29$ $\mathrm{pmol} / \mathrm{kg} / \mathrm{d}, n=3$ ) similar to those of the healthy control group.

$D N A$ damage caused by AZT in mice: urinary excretion of 8-oxo-dG in mice treated with $A Z T$. We also tested the effect of AZT (at doses of $10 \mathrm{mg} / \mathrm{kg}$ body wt/d, similar to those taken by patients) on the excretion of 8-oxo-dG in the urine of mice. Controls excreted $18.0 \pm 9.2 \mathrm{pmol} / \mathrm{g}$ body wt/d $(n=6)$ whereas AZT-treated mice excreted $72.8 \pm 59.2 \mathrm{pmol} / \mathrm{g}$ body wt $/ \mathrm{d}(n=$ $10, P<0.05)$. This was prevented by antioxidants: mice treated with AZT and vitamins $\mathrm{C}$ and E excreted 15.3 \pm 4.1 $(n=8, P<0.05)($ Fig. $1 B)$.

Table I. Effects of AZT and Antioxidant Vitamins ( $C$ and E) on GSH and GSSG from Total Homogenate of Mouse Skeletal Muscle (Quadriceps)

\begin{tabular}{lccc}
\hline & GSH & GSSG & $($ GSSG/GSH $) \times 100$ \\
\hline & $n m o l / g$ & $n m o l / g$ & \\
Control & $948 \pm 109(9)$ & $18.6 \pm 8.8(7)$ & $1.89 \pm 0.85(7)$ \\
AZT & $902 \pm 110(8)$ & $59.8 \pm 26.1(8)^{*}$ & $6.59 \pm 2.75(8)^{*}$ \\
AZT and antioxi- & & & \\
$\quad$ dant vitamins & $992 \pm 98(8)$ & $26.0 \pm 9.4(8)^{\ddagger}$ & $2.53 \pm 0.97(8)^{\ddagger}$
\end{tabular}

Data are means $\pm S D$, with the number of observations in parentheses. Statistical significance is expressed as follows: $* P<0.05$ versus the control group; ${ }^{\ddagger} P<0.05$ versus the AZT-treated group.
Serum activity of muscle damage marker enzymes in AZTtreated mice: effect of antioxidant vitamins ( $C$ and $E)$. Classic marker enzymes of skeletal muscle damage were measured in serum from three experimental groups. CK activity was increased from $1,645 \pm 966(n=8)$ to $2,407 \pm 558$ U/liter $(n=12)$ $(P<0.05)$. AST activity was also statistically increased from $93 \pm 34(n=8)$ to $135 \pm 43 \mathrm{U} /$ liter $(n=12)(P<0.05)$. Finally, LDH activity was also statistically increased from $389 \pm 187$ $(n=7)$ to $707 \pm 243 \mathrm{U} /$ liter $(n=13)(P<0.05)$. Vitamins $\mathrm{C}$ and $\mathrm{E}$ prevented the increase in enzyme activities caused by AZT (Fig. 2).

Antioxidant vitamins ( $C$ and $E$ ) decrease AZT-induced glutathione oxidation in homogenate from mouse skeletal muscle. Treatment with AZT did not cause a significant decrease in GSH in total muscle homogenate. However, GSSG concentration increased significantly in the AZT-treated group when compared with controls. These results show that AZT induces an oxidation of glutathione in mouse skeletal muscle. Treatment with antioxidant vitamins prevented the AZT-induced glutathione oxidation (Table I). The effect of AZT and antioxidant vitamins ( $\mathrm{C}$ and $\mathrm{E}$ ) on the skeletal muscle GSSG/GSH ratio (values for the ratio show GSSG as a percentage of GSH) followed a similar pattern. Values for the AZT-treated group $(6.59 \pm 2.75, n=8)$ show an increase when compared with the control group $(1.89 \pm 0.89, n=7, P<0.05)$. Treatment with antioxidant vitamins prevented the AZT-induced increase in GSSG in muscle homogenate (Table I).

AZT causes an increase in peroxide production by skeletal muscle mitochondria. To investigate the cause of oxidative damage that we observed in skeletal muscle mitochondria, we measured the effect of AZT on the rate of peroxide production in mitochondria from skeletal muscle. AZT causes a marked increase in peroxide production in mitochondria from skeletal muscle (137 \pm 26 fluorescence units, $n=3)$ when compared with the control group $(12.4 \pm 1.8$ fluorescence units, $n=$ $3, P<0.001)$. This effect was completely abolished $(22.1 \pm 14.8$ fluorescence units, $n=4, P<0.001)$ when mice were fed a diet supplemented with vitamins $\mathrm{C}$ and $\mathrm{E}$ (Fig. 3).

AZT induces an oxidation of mt glutathione in mouse skeletal muscle. Table II shows that mitochondria from mouse skeletal muscle treated with AZT have an increased level of GSSG; oral administration of antioxidant vitamins (C and E) prevents this change. Changes in the GSSG/GSH ratio followed a similar pattern, showing that AZT induces a prooxidative status in mitochondria. Values of the AZT-treated group $(4.24 \pm 0.45, n=3)$ are higher than those of controls $(2.19 \pm$ 


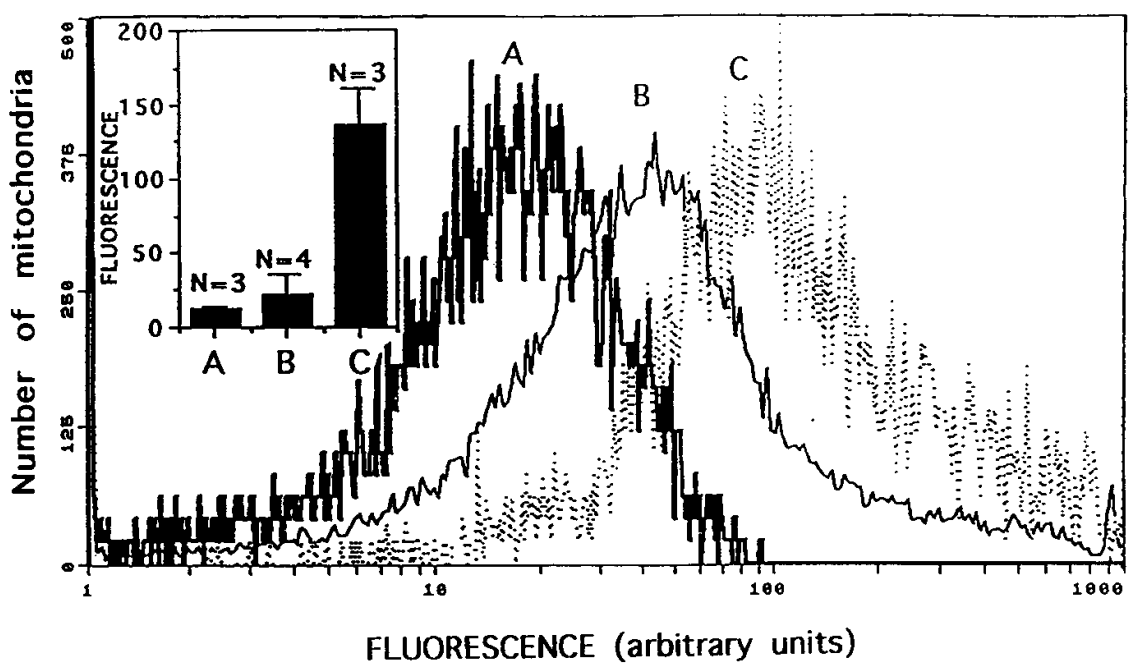

Figure 3. Peroxide generation by isolated skeletal muscle mitochondria from mice treated with AZT and antioxidant vitamins ( $\mathrm{C}$ and $\mathrm{E}$ ). A histogram of one representative experiment is shown. $(A)$ Control mice; $(B)$ mice treated with AZT and vitamins $\mathrm{C}$ and $\mathrm{E}$; and $(C)$ mice treated with AZT only. (Inset) Values for three to four experiments are plotted. Peroxide formation in the AZT-treated group $(C)$ was significantly higher $(P<0.001)$ than in groups $A$ (control) and $B$ (mice treated with AZT and antioxidant vitamins).
$0.28, n=3, P<0.05)$. Antioxidant vitamins prevent AZTinduced oxidation of mt glutathione (Table II).

$A Z T$ causes an increase in mt MDA levels from mouse skeletal muscle. AZT causes an increase in lipoperoxide production in mitochondria that is detected as an increase in MDA levels in skeletal muscle mitochondria. This effect was abolished when mice were fed a diet supplemented with vitamins $\mathrm{C}$ and $\mathrm{E}$ (Table III).

AZT causes oxidative damage to mtDNA from mouse skeletal muscle. The fact that urinary excretion of 8-oxo-dG (Fig. 1) is increased in patients and mice who receive AZT prompted us to study the possible effect of this drug on oxidative damage to mtDNA from skeletal muscle in mice. Table III shows that AZT causes an increase of $>100 \%$ in the levels of 8 -oxo-dG when compared with controls (controls: $0.795 \pm 0.383 \mathrm{pmol} / \mu \mathrm{g}$ mtDNA, $n=4$; AZT-treated: $1.748 \pm 0.568 \mathrm{pmol} / \mu \mathrm{g} \mathrm{mtDNA}$, $n=5, P<0.05)$. This change is completely prevented by the oral administration of antioxidant vitamins $(0.396 \pm 0.156 \mathrm{pmol} /$ $\mu \mathrm{g}$ mtDNA, $n=4, P<0.01)$.

Morphological analysis of mouse skeletal muscle by electron microscopy: antioxidants prevent ultrastructural damage to mitochondria caused by AZT. Fig. 4 shows that treatment with AZT causes considerable damage to muscle mitochondria, which includes swelling and severe disorganization of the internal $\mathrm{mt}$ architecture with cristae disruption. Treatment with antioxidant vitamins prevented this damage. These morpho-

Table II. Effects of AZT and Antioxidant Vitamins ( $C$ and E) on GSH and GSSG of Isolated Mitochondria from Mouse Skeletal Muscle

\begin{tabular}{|c|c|c|c|}
\hline & GSH & GSSG & $(\mathrm{GSSG} / \mathrm{GSH}) \times 100$ \\
\hline & $\mathrm{pmol} / \mathrm{mg}$ protein & $\mathrm{pmol} / \mathrm{mg}$ protein & \\
\hline Control & $603 \pm 406(3)$ & $8.1 \pm 3.0(3)$ & $2.19 \pm 0.28$ (3) \\
\hline $\mathrm{AZT}$ & $320 \pm 177$ (3) & $13.0 \pm 2.0(4)^{*}$ & $4.24 \pm 0.45(3)^{*}$ \\
\hline $\begin{array}{c}\text { AZT and antioxi- } \\
\text { dant vitamins }\end{array}$ & $414 \pm 49(3)$ & $7.6 \pm 1.5(3)^{\ddagger}$ & $1.85 \pm 0.33(3)^{\ddagger}$ \\
\hline
\end{tabular}

Data are means $\pm \mathrm{SD}$, with the number of observations in parentheses. Statistical significance is expressed as follows: $* P<0.05$ versus the control group; ${ }^{\ddagger} P<0.05$ versus the AZT-treated group. logical observations are in keeping with the protective effect of antioxidants on AZT-induced oxidative damage to mtDNA and other biochemical parameters we have observed.

\section{Discussion}

8-oxo-dG is one of the best indicators of oxidative damage to DNA (29), and furthermore, we found previously that changes in 8-oxo-dG correlate with other signs of oxidative stress such as glutathione oxidation (9). Urinary excretion of 8-oxo-dG is related to its level in cellular DNA (nuclear DNA and mtDNA). Ames and co-workers (17, 29-31) showed that urinary excretion of 8-oxo-dG can be taken as a good biological marker of in vivo oxidative DNA damage. We have found that AZT-treated patients excrete significantly more 8-oxo-dG in urine than untreated patients (see Fig. $1 A$ ). AZT also causes $\mathrm{mt}$ myopathy $(3,5)$. Due to obvious ethical reasons it was difficult to obtain samples of mtDNA from the muscle of AZTtreated patients. Thus, we measured the levels of 8-oxo-dG in urine and in mtDNA of AZT-treated mice and found that they were higher than in controls. We found an increased urinary excretion of 8-oxo-dG (see Fig. $1 B$ ) and an increased level of 8-oxo-dG in the mtDNA of AZT-treated mice.

It is well known that AZT causes muscle mt myopathy, with ultrastructural changes in skeletal muscle in humans and animals $(3,5)$. These changes are accompanied by decreased

Table III. Effects of AZT and Antioxidant Vitamins ( $C$ and E) on mt levels of MDA and on Levels of 8-oxo-dG in mtDNA from Mouse Skeletal Muscle

\begin{tabular}{|c|c|c|}
\hline & MDA & 8-oxo-dG \\
\hline & nmol/mg protein & $\mathrm{pmol} / \mu \mathrm{g} m t D N A$ \\
\hline Control & $28.6 \pm 11.7(3)$ & $0.78 \pm 0.38$ \\
\hline $\mathrm{AZT}$ & $52.1 \pm 4.1(4)^{*}$ & $1.75 \pm 0.57(5) *$ \\
\hline AZT and antioxidant vitamins & $41.5 \pm 2.0(3)^{\ddagger}$ & $0.40 \pm 0.16(4)^{\S}$ \\
\hline
\end{tabular}

Data are means $\pm \mathrm{SD}$, with the number of observations in parentheses. Statistical significance is expressed as follows: $* P<0.05$ versus the control group; and ${ }^{\ddagger} P<0.05$, or ${ }^{\S} P<0.01$ versus the AZT-treated group. 

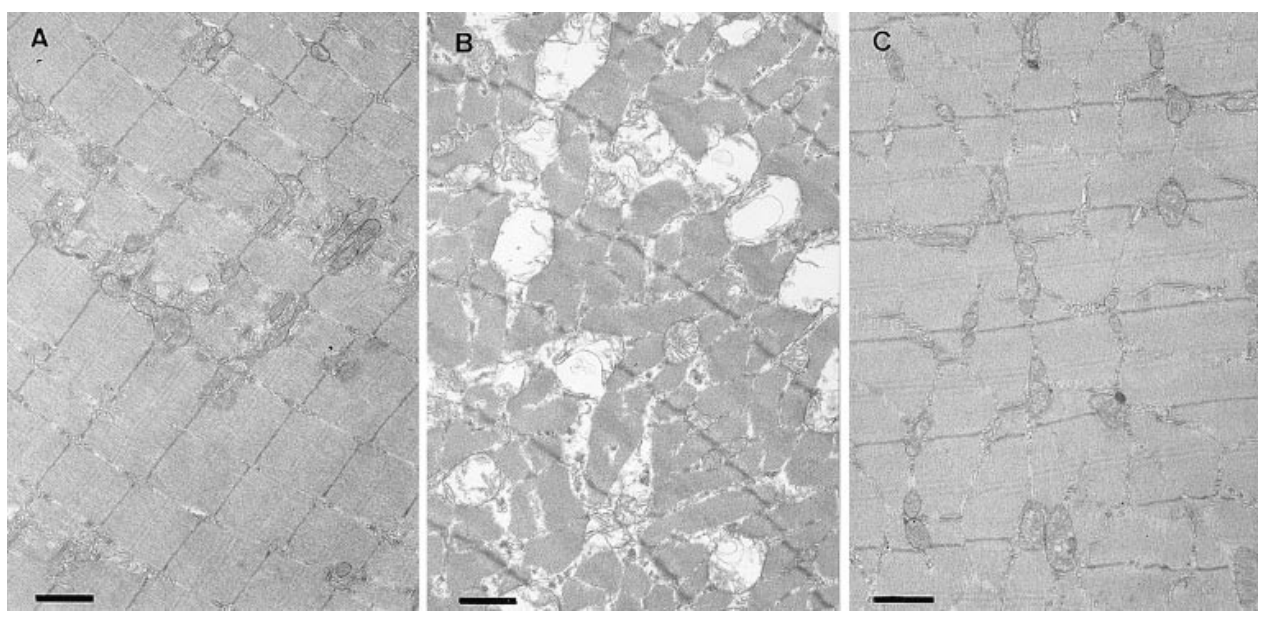

Figure 4. Representative electron photomicrographs of skeletal muscle. Control mice $(A)$, mice treated with AZT $(10 \mathrm{mg} / \mathrm{kg}$ body wt/d) for $35 \mathrm{~d}(B)$, and mice treated with AZT and antioxidant vitamins $(\mathrm{C}$ and $\mathrm{E}$ ) simultaneously for $35 \mathrm{~d}(C)$. Scale bar is equal to $10 \mu \mathrm{m}$.

mtDNA, mtRNA, and mt polypeptide synthesis (5). However, the mechanism of such myopathy was previously unknown. Here we show that AZT causes an oxidation of mtDNA, as evidenced by increased levels of 8-oxo-dG in mtDNA isolated from mouse skeletal muscle (Table III), and that this correlates with changes in the urinary excretion of 8-oxo-dG. Other signs of oxidative stress, such as MDA formation (32-35), or glutathione oxidation (9), also occur in mitochondria isolated from the skeletal muscle of AZT-treated animals (Table II) (see Fig. 3 B). As a consequence, AZT may affect whole muscle cells as indicated by an increase in plasma activity of cytoplasmic enzymes such as CK or LDH (see Fig. 2).

These effects are probably due to an increased peroxide formation by mitochondria from the muscle of AZT-treated animals. Indeed, the increase in peroxide production (see Fig. 3) may explain the signs of oxidative damage to mt macromolecules such as DNA, mt lipids (MDA), and the oxidation of glutathione.

Several studies have documented that AZT induces inhibition of DNA polymerase gamma, which is responsible for mtDNA replication (36). A possible link between this decrease in DNA replication and the increase in free-radical production that we find is that as a result of lowered mtDNA replication, $\mathrm{mt}$ turnover is decreased. Thus, mitochondria will not be properly renewed in the cell, and old mitochondria will remain in the cell. We have found that mitochondria from old animals produce more peroxides than those from young ones and suffer from oxidative stress (28). In any case, oxidative stress directly or indirectly contributes to mtDNA damage caused by AZT, and treatment with antioxidant vitamins prevents such mt damage.

In summary, treatment of animals with vitamins $\mathrm{C}$ and $\mathrm{E}$ protects against signs of ultrastructural $\mathrm{mt}$ damage (see Fig. 4) and prevents the oxidation of muscle intra-mt components induced by AZT. These protective effects provide biochemical bases for preventing AZT-induced mt myopathy using oral supplementation with antioxidant vitamins such as $\mathrm{C}$ and $\mathrm{E}$.

\section{Acknowledgments}

We thank Juana Belloch, Nuria García, and Salvador Souan for skillful technical assistance and Marilyn R. Noyes for revising the typescript.
This work was supported by grants SAF95/0558 and FIS95/0940 (José Viña).

\section{References}

1. Furman, P., J.A. Fyfe, and M.H. St. Clair. 1990. Phosphorylation of $3^{\prime}$ azido- 3 -deoxythymidine and selective interaction of the $5^{\prime}$-triphosphate with human immunodeficiency virus reverse transcriptase. Proc. Natl. Acad. Sci. USA. 83:8333-8337.

2. Yarchoan, R., H. Mitsuda, C.E. Myers, and S. Broder. 1989. Clinical pharmacology of $3^{\prime}$-azido-2',3'-dideoxythymidine (zidovudine) and related dideoxynucleosides. N. Engl. J. Med. 321:726-738.

3. Dalakas, M., Y. Illa, G.H. Pezeshkpour, J.P. Laukatis, B. Cohen, and J.L. Griffin. 1990. Mitochondrial myopathy caused by long-term zidovudine theraphy. N. Engl. J. Med. 322:1098-1105.

4. Arnaudo, E., M. Dalakas, S. Shanske, C.T. Moraes, S. Dimauro, and E.A. Schon. 1991. Depletion of muscle mitochondrial DNA in AIDS patients with zidovudine-induced myopathy. Lancet. 337:508-510.

5. Lewis, W., B. Gonzalez, A. Chomyn, and T. Papoian. 1992. Zidovudine induces molecular, biochemical, and ultrastructural changes in rat skeletal muscle mitochondria. J. Clin. Invest. 89:1354-1360.

6. Hayakawa, M., T. Ogawa, S. Sugiyama, M. Tanaka, and T. Ozawa. 1991. Massive conversion of guanosine to 8-hydroxy-guanosine in mouse liver mitochondrial DNA by administration of azidothymidine. Biochem. Biophys. Res. Commun. 176:87-93.

7. Luft, R. 1994. The development of mitochondrial medicine. Proc. Natl. Acad. Sci. USA. 91:8731-8738.

8. Johns, D.R. 1995. Mitochondrial DNA and disease. N. Engl. J. Med. 333: 638-644.

9. García de la Asunción, J., A. Millán, R. Plá, L. Bruseghini, A. Esteras, F.V. Pallardo, J. Sastre, and J. Viña. 1996. Mitochondrial glutathione oxidation correlates with age-associated oxidative damage to mitochondrial DNA. FASEB (Fed. Am. Soc. Exp. Biol.) J. 10:333-338.

10. Levine, M., C. Conry-Cantinela, Y. Wang, R.W. Welch, P.W. Washko, K.R. Dhariwal, J.B. Park, A. Lazarev, J.F. Graumlich, J. King, et al. 1996. Vitamin C pharmacokinetics in healthy volunteers: evidence for a recommended dietary allowance. Proc. Natl. Acad. Sci. USA. 93:3704-3709.

11. Kappus, H., and A.T. Diplock. 1992. Tolerance and safety of vitamin E: a toxicological position report. Free Rad. Biol. Med. 13:55-74.

12. Rickwood, D.W., M.T. Wilson, and V.M. Darley-Usmar. 1987. Isolation and characteristics of intact mitochondria. In Mitochondria, a Practical Approach. V.M. Darley-Ulmar, M.T. Wilson, and D. Rickwood, editors. IRL Press, Washington DC. 4-6.

13. LaTorre, A., A. Moya, and F.J. Ayala. 1986. Evolution of mitochondrial DNA in Drosophila suboscura. Proc. Natl. Acad. Sci. USA. 83:8649-8653.

14. Richter, C., J.W. Park, and B.N. Ames. 1988. Normal oxidative damage to mitochondrial and nuclear DNA is extensive. Proc. Natl. Acad. Sci. USA. 85: 6465-6467.

15. Bibb, M.J., R.A. Van Etten, C.T. Wright, M.W. Walberg, and D.A. Calyton. 1981. Sequence and gene organization of mouse mitochondrial DNA. Cell. 26:167-180.

16. Beckman, K., and B. Ames. 1996. Detection and quantitation of oxidative adducts of mtDNA. Meth. Enzymol. 264:442-453.

17. Shigenaga, M.K., C. Gimeno, and B.N. Ames. 1989. Urinary 8-hydroxy2 '-deoxyguanosine as a biological marker of in vivo oxidative DNA damage. 
Proc. Natl. Acad. Sci. USA. 86:9697-9701.

18. Brow, R.K., A. McBurney, J. Lunec, and K. Frank. 1995. Oxidative damage to DNA in patients with cystic fibrosis. Free Rad. Biol. Med. 18:801806.

19. Shigenaga, M., E.N. Aboujaoude, Q. Chen, and B.N. Ames. 1994. Assay of oxidative DNA damage biomarkers 8-oxo-2'-deoxyguanosine and 8-oxoguanine in nuclear DNA and biological fluids by high performance liquid chromatography with electrochemical detection. Meth. Enzymol. 234:16-33.

20. Bergmeyer, H.U. 1974. Methods of Enzymatic Analysis. Academic Press, New York.

21. Brigelius, R., C. Merckel, T. Akerboom, and H. Sies. 1983. Identification and quantification of glutathione in hepatic protein mixed disulfides and its relationship to glutathione disulfide. Biochem. Pharmacol. 32:2529-2534.

22. Asensi, M., J. Sastre, F.V. Pallardo, J. García de la Asunción, J. Estrela, and J. Viña. 1994. A high performance liquid chromatography method for measurement of glutathione in biological samples. Anal. Biochem. 217:323-328.

23. Viña, J., J. Sastre, M. Asensi, and L. Packer. 1995. Assay of blood glutathione oxidation during physical exercise. Meth. Enzymol. 251:237-243.

24. Wong, S.H.Y., J.A. Knight, S.M. Hopfer, O. Zaharia, C.N. Leach, and F.W. Sunderman. 1987. Lipoperoxides in plasma as measured by liquid-chromatographic separation of malondialdehyde-thiobarbituric acid adduct. Clin. Chem. 33:214-220.

25. Gutteridge, J.M.C. 1975. The use of standards for malonyldialdehyde. Anal. Biochem. 69:518-526.

26. Chen, L.B. 1988. Mitochondrial membrane potential in living cells. Ann. Rev. Cell Biol. 4:155-181.
27. Royall, J.A., and H. Ischiropoulos. 1993. Evaluation of $2^{\prime}-7^{\prime}$-dichlorofluorescein and dihydrorhodamine 123 as fluorescent probes for intracellular $\mathrm{H}_{2} \mathrm{O}_{2}$ in cultured endothelial cells. Arch. Biochem. Biophys. 302:348-355.

28. Sastre, J., F.V. Pallardó, R. Plá, A. Pellín, G. Juan, J.E. O'Connor, J.M. Estrela, J. Miquel, and J. Viña. 1996. Aging of the liver: age-associated mitochondrial damage in intact hepatocytes. Hepatology. 24:1199-1205.

29. Shigenaga, M.K., J.W. Park, K. Cundy, C. Gimeno, and B.N. Ames. 1990. In vivo oxidative DNA damage: measurement of 8-hydroxy-2'-deoxyguanosine in DNA and urine by high-performance liquid chromatography with electrochemical detection. Meth. Enzymol. 186:521-530.

30. Fraga, C.G., M.K. Shigenaga, J.W. Park, P. Degan, and B.N. Ames. 1990. Oxidative damage to DNA during aging: 8-hydroxy-2'-deoxyguanosine in rat organ DNA and urine. Proc. Natl. Acad. Sci. USA. 87:4533-4537.

31. Ames, B.N., M.K. Shigenaga, and T.M. Hagen. 1993. Oxidants, antioxidants, and the degenerative diseases of aging. Proc. Natl. Acad. Sci. USA. 90 7915-7922.

32. Slater, T.F. 1984. Free-radical mechanisms in tissue injury. Biochem. J. 222:1-15.

33. Halliwell, B., and J.M.C. Gutteridge. 1985. The importance of free-radicals and catalytic metal ions in human diseases. Mol. Aspects Med. 8:89-193.

34. Sevanian, A., and P. Hochstein. 1985. Mechanisms and consequences of lipid peroxidation in biological systems. Ann. Rev. Nutr. 5:365-390.

35. Comporti, M. 1985. Lipid peroxidation and cellular damage in toxic liver injury. Lab. Invest. 53:599-623.

36. Bolden, A., G. Pedrali, and A. Weissbach. 1977. DNA polymerase of mitochondria is a gamma-polymerase. J. Biol. Chem. 252:3351-3356. 